\title{
ETNOGRAFÍA DE LA ESCUELA A TRAVÉS DE LAS MEMORIAS DE PRÁCTICAS DE ENSEÑANZA EN CANARIAS (ESPAÑA)
}

Teresa González-Peréz*

\section{RESUMEN}

Las Prácticas curriculares de Enseñanza se configuran como actividades académicas obligatorias en los planes de estudio de Magisterio. Nuestro objetivo es estudiar la escuela en Canarias entre 1936 y 1949 a través del fondo documental de la Escuela de Magisterio de La Laguna que custodia las Memorias de Prácticas inéditas. El análisis de estas memorias nos permite sumergirnos en la práctica escolar en el periodo de la guerra y posguerra. Esta investigación permite la reconstrucción histórica de la práctica educativa y poner en valor la metodología etnográfica.

Palabras clave: Memorias de Prácticas, magisterio, etnografía escolar, escuela, franquismo.

* Universidad de La Laguna, Santa Cruz de Tenerife, Espanha. 


\title{
ETNOGRAFIA DA ESCOLA ATRAVÉS DAS MEMÓRIAS DE PRÁTICAS DE ENSINO NAS ILHAS CANÁRIAS (ESPANHA).
}

\section{RESUMO}

As Práticas Curriculares de Ensino configuram-se como atividades acadêmicas obrigatórias em da qualificação docente. Nosso objetivo é estudar a escola nas Ilhas Canárias entre 1936 e 1949 através do fundo documental da Escola de Ensino de La Laguna que detém os Relatórios de Prática de Ensino, ainda não publicados. A análise dessas memórias nos permite mergulhar na prática escolar no período da guerra e do pós-guerra. Esta pesquisa permite a reconstrução histórica da prática educativa e valoriza a metodologia etnográfica.

Palavras-chave: Relatórios Práticos, ensino, etnografia escolar, escola, Franquismo.

\section{ETHNOGRAPHY OF THE SCHOOL THROUGH THE MEMORIES OF TEAHING PRACTICES IN THE CANARY ISLANDS (SPAIN).}

\begin{abstract}
The curricular Teaching Practices were configured as compulsory academic activities within the curricula of the Teaching qualification. Our objective is to study the school in the Canary Islands between 1936 and 1949 through the documentary fund of the "School of Teaching of La Laguna" that holds the unpublished Practical Reports. The analysis of these memories allows us to immerse ourselves in the culture and school practice in the period of war and postwar. This research allows the historical reconstruction of the educational practice and to value the ethnographic methodology.
\end{abstract}

Keywords: Practice Reports, teaching, school ethnography, school, francoism.

\section{ETHNOGRAPHIE DE L'ECOLE A TRAVERS LES MEMOIRES DES PRATIQUES PEDAGOGIQUES AUX CANARIES (ESPAGNE).}

\section{RESUME}

Les pratiques pédagogiques ont été configurées comme activités académiques obligatoires dans les plans d'études du diplôme d'enseignement. Notre objectif est d'étudier l'école dans les îles Canaries entre 1936 et 1949, à travers la collection documentaire de l'école d'enseignement de «La Laguna » qui garde les mémoires de pratiques inédites. L'analyse de ces mémoires nous permet d'approfondir dans la culture et la pratique scolaire de la guerre et de l'après-guerre. Cette recherche permet la reconstruction historique de la pratique éducative et valorise la méthodologie ethnographique.

Mots-clés: Mémoires de pratiques, enseignement, ethnographie scolaire, ecole, franquisme. 


\section{INTRODUCCIÓN}

Abordar el estudio histórico de la cultura escolar ${ }^{1}$ en el pasado reciente exige emplear otras fuentes para conocer esa realidad. La utilización de distintos documentos y registros nos acercan a la escuela y nos permiten lanzar la mirada al ayer de la escolaridad, de las prácticas y los usos escolares (ESCOLANO 2007 y 2010). La renovación metodológica en las últimas décadas ha abierto espacio a un abanico de fuentes. Por referir algunas desde los útiles escolares, libros, cuadernos, materiales didácticos, imágenes, a las memorias académicas junto a las fuentes orales permiten reconstruir la práctica escolar durante el franquismo.

La cultura escolar (el discurso político emanado de las leyes y normas impuestas engloba al normativo, al teórico y al empírico) regulan la educación, pero las teorías y prácticas docentes desarrolladas en el transcurso del tiempo influyen en las formas de enseñar de los profesionales de la educación. No obstante, en ocasiones se ha evidenciado la distancia entre lo prescrito en las normas y la aplicación didáctica (MARTÍN, 2015). Una fuente de primer orden para conocer la etnografía de la escuela la constituyen las memorias de prácticas de enseñanza que tienen que elaborar y redactar el alumnado de magisterio tras su paso por las escuelas (MARTÍN, 2011). Las prácticas curriculares de enseñanza forman parte de la cultura empírica, están en consonancia con el modelo teórico educativo imperante y con el plan de estudios en vigor. Las prácticas de enseñanza, como materia curricular obligatoria en los estudios de Magisterio, evolucionan con los planes de estudio en función de exigencias sociales.

Las prácticas escolares se constituyen como indicios que atribuyen significado a los discursos y planteamientos teóricos que marcan su uso en la escuela. El actuar del maestro desvela un paradigma atribuido a códigos implícitos en los modelos pedagógicos analizados. Se pretende con este trabajo romper - de cara a los alumnos- con un modelo de formación basado en la utilización de fórmulas comunes para dar

\footnotetext{
${ }^{1}$ Financiado con la ayuda para proyectos de investigación del Plan Propio del Vicerrectorado de Investigación (Universidad de La Laguna).
} 
entrada a la individualidad del que aprende y se forma indagando, reflexionando acerca de su proceder dentro del aula e investigando sobre educación para extraer conclusiones didácticas y docentes. (MARTÍN, 2011, p. 48).

Las prácticas curriculares de enseñanza se configuraban como actividades académicas obligatorias dentro de los planes de estudio de la titulación de Magisterio. Reguladas por la normativa específica tenían una finalidad formativa con el objetivo del aprendizaje profesional. Se integraban en el plan de estudios diseñadas en base a unos objetivos y competencias académicas. A través de ellas se podían aplicar los conocimientos teóricos y prácticos adquiridos durante la preparación académica en las escuelas de magisterio. Unas prácticas externas al centro donde se formaban, para cuyo desarrollo contaban con la orientación y asesoramiento de la maestra titular que les ayudaba a resolver las dudas metodológicas.

Los estudiosos de la educación afirman que las prácticas escolares
forman parte de la tradición corporativa de los enseñantes que se
transmiten de manera subliminal entre ellos y que responden también
a concepciones teóricas proyectadas en la escuela. Dos de estos modelos
pedagógicos de concebir la enseñanza, la escuela tradicional y la escuela
nueva, han planteado sus maneras de entender el mundo y la vida.
Dispares fórmulas de concebir al hombre y la educación que éste debe
recibir, transmitidas por medio del hacer profesional del maestro. La
aproximación a la cultura empírica permite comprobar el grado de
adaptación a una u otra concepción pedagógica. (MARTín, 2011, p.47).

Las memorias de prácticas constituyen un acervo documental importante, que aportan información sobre la realidad escolar. El desarrollo de la investigación sobre la formación del magisterio en Canarias durante la guerra y posguerra nos ha llevado a estudiar las prácticas de enseñanza. Nos hemos detenido en analizar las memorias inéditas presentadas por las estudiantes, documentos autógrafos y subjetivos que suministran un caudal de información. Las maestras en formación narran como ha sido su experiencia y la actividad pedagógica cotidiana en las escuelas donde hicieron sus prácticas, bajo la tutela 
de una maestra titular. Como observadoras directas reflejan la situación de las infraestructuras, el edificio escolar, los patios para el recreo, la ventilación, los materiales, la organización escolar, las imposiciones ideológicas, los contenidos patrióticos y el control de la práctica pedagógica. Las memorias también informan de la didáctica y metodología docente, en la mayoría adaptada a los requerimientos del nuevo orden impuesto pero reflejan en algunos casos, el uso de innovaciones didácticas propias de épocas anteriores.

Nos adentramos en la educación y analizamos su evolución dado que las Islas Canarias quedaron bajo poder nacional desde el mismo 18 de julio de 1936. No fueron escenario de guerra si bien hubo algunos focos de resistencia, el modelo nacional se impuso desde los primeros momentos (MORENTE, 2001; RIVAS, 2015). Añadir que el territorio insular, alejado de la geografía española peninsular, reprodujo fielmente idénticas formas que rige el discurso educativo del nacionalcatolicismo (LÓPEZ, 2017).

En el marco de este trabajo pretendemos conocer la realidad escolar en Canarias (España) en los años de la guerra y posguerra (1936-1949) a través de las memorias de prácticas de las estudiantes de magisterio. De este objetivo general se derivan los siguientes objetivos específicos: 1) Comprobar si las directrices y normas aprobadas se impusieron de forma inmediata o en cambio siguieron aplicando el modelo innovador republicano. De manera que pretendemos constatar si la práctica escolar cambió radicalmente y se impuso el patrón autoritario o continuaron con la aplicación docente renovadora. 2) Analizar si se construyó el modelo de cultura escolar que pretendía imponer el franquismo en un momento de uniformidad de la enseñanza primaria. 3) Pretendemos contribuir a la historia de la educación, poniendo en valor las memorias de prácticas como fuente documental que suministra información sobre la cultura empírica de la escuela.

Para esta investigación de carácter histórico educativo contamos con antecedentes de estudio para otras zonas del territorio español, como es el caso de las memorias escolares en Castilla-León de Martín y Ramos (2017) y las 
memorias de prácticas de Baleares de Barceló, Comas y Sureda (2016). También las memorias de oposiciones de la posguerra estudiadas por Barceló, Comas y Pozo (2018). Añadir los estudios de María del Mar del Pozo y Teresa Rabazas (2013) utilizando la colección de memorias de prácticas de los estudiantes de pedagogía del Fondo Anselmo Romero Marín del Museo M. B. Cossío de la Universidad Complutense de Madrid. También otros autores han utilizado las Memorias para el estudio de épocas anteriores, como Fernández Soria y Agulló (2002). El trabajo de The Black Box of Schooling (BRASTER, GROSVENOR, DEL POZO, 2011) ha sido pionero en aportar nuevos testimonios de la intrahistoria escolar.

La metodología histórico-educativa se beneficia de las aportaciones de otras ciencias afines, como la historiografía, antropología y etnografía, que contribuyen a explicar la realidad cotidiana en las escuelas canarias de la guerra y la posguerra. También la etnografía aporta un enfoque subjetivo y de género. Nos cuestionamos cómo era la vida de la escuela tras el levantamiento militar, si hubo una ruptura con la práctica anterior y si se define un nuevo modelo educativo.

Nuestra hipótesis de partida se sustenta en que la práctica escolar no cambió radicalmente durante la guerra y la posguerra, continuaron empleando la pedagogía activa. El modelo de cultura escolar que pretendía imponer el franquismo se construyó sobre una base ideológica, afianzada con la simbología y manifestaciones del nacionalcatolicismo, pero subyace la pedagogía renovadora en un momento de uniformidad de la enseñanza primaria.

Como fuentes empleamos las memorias de prácticas inéditas conservadas en el Fondo de Magisterio del Archivo histórico de la Universidad de La Laguna. Hemos examinado una muestra al azar de cincuenta memorias inéditas, correspondiente a diferentes planes de estudio de magisterio vigentes en la época objeto de esta investigación. Localizamos memorias del Plan 1914, Plan Profesional de 1931, Plan Bachiller 1940, Plan 1942 y Plan 1945. Las alumnas del Plan 1914 y del Plan Profesional de 1931 que no habían terminado de cursar 
sus estudios realizaron las prácticas curriculares bajo el gobierno militar. De manera que habían recibido una formación diferente, sin embargo, aplicaron de forma inmediata los postulados del nuevo orden político que se imponía a la fuerza en España, con el avance de las tropas, a partir del 18 de julio de 1936. Las memorias corresponden a las alumnas, y por tanto referidas a las escuelas de niñas de diferentes áreas geográficas de Canarias, fundamentalmente de las islas de Tenerife, La Palma y La Gomera. Es decir, del sector occidental, dado que la Escuela de Magisterio estudiada radicaba en la ciudad de San Cristóbal de La Laguna, en Tenerife. También se revisaron los libros de registro de matrícula de enseñanza oficial y los libros de registro de matrícula de enseñanza no oficial así como las instancias de solicitud de prácticas.

\section{LAS PRÁCTICAS CURRICULARES DE LAS ALUMNAS DE LA ESCUELA DE MAGISTERIO DE LA LAGUNA}

Las estudiantes, aprendizas de maestras, realizaron las prácticas curriculares de enseñanza bajo la supervisión de la maestra titular en la escuela aneja, conocida como "escuela de prácticas". También se ejercitaron en las escuelas nacionales graduadas y en escuelas nacionales unitarias bajo las orientaciones de la respectiva maestra titular. Las alumnas de enseñanza no oficial concertaban previamente el la escuela donde realizar las prácticas, con la aceptación de la maestra, y comunicaban a través de una instancia a la directora de la Escuela de Magisterio. Todo un protocolo del que se llevaba un registro con el nombre y apellido de la alumna, la escuela, la maestra y la localidad (INSTANCIAS de Solicitud de Prácticas. Caja 140).

La matrícula en régimen de enseñanza no oficial era elevada, un hecho que se justifica tanto por la dispersión del hábitat como por la orografía, los limitados recursos económicos de las familias y las dificultades de comunicación intrainsulares. A ello añadir la doble insularidad, en el sentido de que las alumnas de otras islas tenían que desplazarse a Tenerife y no era asequible a las economías 
familiares. La solución era acceder a través de la enseñanza no oficial y presentarse a los exámenes en las convocatorias ordinarias o extraordinarias. Las alumnas que solicitaban la dispensa de escolaridad esgrimían sus razones, entre ellas, la edad, la lejanía, falta de recursos económicos, estar casada con hijos pequeños, etc. En el centro se consideraban, tenían en cuenta la edad y las circunstancias personales para estimar la solicitud. Por dichas razones, una parte importante de las alumnas accedía a la titulación de magisterio a través de enseñanza no oficial, aunque igualmente debían realizar y acreditar el periodo de prácticas de enseñanza reglamentario.

Dada la importancia del sistema de matrícula en régimen no oficial las estudiantes realizaban las correspondientes prácticas en escuelas públicas, ubicadas en zonas urbanas, mayoritariamente en los núcleos de la cuidad o en la periferia, pero también hicieron prácticas en las escuelas de zonas rurales. Las prácticas curriculares de enseñanza generalmente se desarrollaron en el área metropolitana de Tenerife, es decir en San Cristóbal de La Laguna y en Santa Cruz de Tenerife, zona próxima a la escuela de magisterio. En Santa Cruz de Tenerife, las escuelas graduadas de niñas de los barrios capitalinos de Duggi, Los Lavaderos, Salamanca, El Norte, El Cabo y García Escámez fueron las más frecuentadas por las alumnas en prácticas ${ }^{2}$.

En La Laguna, la escuela graduada Aneja era la escuela modelo en la que regularmente hacían las prácticas, pero también acudían a aprender a enseñar en las escuelas graduadas de niñas $\mathrm{n}^{0} 1 \mathrm{y} \mathrm{n}^{0} 2$, así como a las escuelas de los barrios de Taco, San Bartolomé, La Cuesta y Geneto. Entre las escuelas unitarias o graduadas situadas en otros pueblos o en zonas rurales señalar al respecto las escuelas públicas de niñas de Tacoronte, Tejina, Tegueste, El Sauzal, La Victoria de Acentejo, Puerto de la Cruz, La Orotava, Realejo Bajo, La Guancha, Icod,

\footnotetext{
${ }^{2}$ Más tarde, en los años de posguerra, las escuelas aparecen con denominaciones diferentes, dado que se modificó o añadió un nombre significado para la época. Por ejemplo, la escuela graduada de niñas del barrio de Duggi pasó a denominarse "San Fernando"; a la escuela del barrio del norte se le llamó "Onésimo Redondo"; a la escuela del barrio de Salamanca se le rotula "José Antonio"; a la escuela graduada del barrio de El Cabo se le designa "Isabel la Católica".
} 
Garachico, Los Silos, Güimar, Arico, Fasnia, Adeje, Arona y otras localidades de Tenerife. En otras islas, en La Palma (Santa Cruz de La Palma, Breña Baja, Fuencaliente, Puntallana, Los Sauces y Mazo) y en La Gomera (San Sebastián y Hermigua). En muchos casos se repiten los centros porque las alumnas concurrían a los mismos en distintas fechas. La mayor variedad de localidades y de ubicación de escuelas se correspondía con las prácticas de las alumnas del Plan Bachiller. Transcurrido el periodo reglamentario de prácticas, las maestras de las respectivas escuelas acreditaban la realización de la actividad desarrollada, informando del correcto desempeño y del compromiso pedagógico de la alumna. Al efecto redactaban y firmaban una certificación, con el visto bueno de la inspectora, donde informaban del correcto desempeño y del compromiso pedagógico de la alumna en prácticas.

Las memorias son muy representativas de la escolaridad de esas décadas. Describen los rasgos dominantes de la enseñanza en la escuela pública (GONZÁLEZ, 2001; 2005). Reflejan el universo escolar, la vida cotidiana en las aulas, los asuntos fundamentales de la cultura escolar, del quehacer pedagógico que tienen una circularidad ideológica aunque estaban presentes los conceptos tradicionales de la pedagogía. La pedagogía renovadora alternaba con las formas arcaicas del patriotismo y catolicismo. Si bien, se proyecta la realidad insular ésta es extensible a otras áreas geográficas porque los hechos son similares. Una experiencia análoga que se proyectaba en otras zonas, manteniendo vínculos entre los condicionantes sociohistóricos y políticos educativos (GONZÁLEZ, 2000; 2001).

Las memorias no son homogéneas, ni en el contenido ni en el número de páginas. Las presentaban manuscritas o mecanografiadas, a veces adornadas en la portada y acompañadas de ilustraciones. Las entregaban de múltiples formas y buena parte de los textos sin paginar. Deducimos que no había unas normas definidas ni unos criterios al que debían someterse para su elaboración. Había flexibilidad pero todas las memorias tienen sus hojas pegadas, grapadas, encuadernadas, anilladas o sujetas con un cordón. Algunas eran más extensas y 
muy explicativas, incluso con 34-35 páginas y un anexo con las hojas de preparación (CONTRERAS, 1946; RAMOS, 1937) y otras más escuetas que no sobrepasaban las 5 páginas (CARRILLO, 1947; HERNÁNDEZ, 1937; PÉREZ, 1937; SOLER, 1947). Varias acompañaban planos de la escuela y dibujos relacionados con las lecciones. No obstante, la mayoría de las memorias tienen una estructura similar y se detienen en analizar fundamentalmente la infraestructura, mobiliario, la metodología, los programas, la enseñanza de doctrina cristiana y la historia sagrada, la formación patriótica, los contenidos y los materiales. A la vez informaban de que las escuelas estaban decoradas con cuadros del caudillo y del "inolvidable José Antonio" (RÍOS, 1943) y las imágenes de la virgen María, la Inmaculada, el Sagrado Corazón y el Cristo. Una decoración, simbología e imaginario que se repite en todos los centros mencionados.

\section{LAS MEMORIAS DE PRÁCTICAS COMO REFLEJO DE LA REALIDAD ESCOLAR DURANTE LA GUERRA Y POSGUERRA}

En Canarias la educación no rompió de forma inmediata con el modelo anterior. Mantuvo formas propias de la pedagogía renovadora, aunque desde las esferas del poder se pretendía generalizar la metodología tradicional y conservadora. La mayoría de docentes no alteraron su práctica y continuaron utilizando la pedagogía innovadora, heredera de la tradición de las corrientes renovadoras. Las maestras seguían aplicando metodologías activas, aunque teñidas por los nuevos postulados patrióticos del nacionalcatolicismo. Así se puede comprobar en los diarios de preparación de lecciones o en las denominadas hojas de preparación, que muchas alumnas acompañaron a sus respectivas memorias. Desde las esferas del poder se prescribió la separación de sexos y se suspendió inmediatamente la coeducación o enseñanza mixta en todas las actividades educativas. La enseñanza era sexista y segregada por sexos, fortalecida con las ideas tradicionales de la pedagogía decimonónica. No 
obstante, hubo escuelas donde perduró la enseñanza mixta, sobre todo, en algunas zonas rurales y en algunos barrios periféricos (CARRERA, 1948; CATALÁN, 1943; DELGADO, 1947; DELGADO, 1949). Las deficiencias apreciadas por la mirada de las aprendices de maestras y su implicación en el acontecer diario de la escuela, en la que incluso sustituyen a las maestras ausentes. Una de las alumnas hizo prácticas en $3^{\circ}$ curso de la escuela práctica aneja y por enfermedad de la maestra fue nombrada sustituta por la sección administrativa de primera enseñanza (RAMOS, 1937). Ese dato indica la insuficiencia de personal docente, máxime si consideramos que estos años se depuró a las maestras y algunas fueron apartadas de la enseñanza (BOLETÍNES 1936; MORENTE, 2001). Del análisis de las memorias extraemos los aspectos más destacados que nos aproximan a la realidad escolar durante la guerra y la posguerra.

\section{LAS INSTALACIONES ESCOLARES}

Todas las memorias informan del edificio, del estado del inmueble, espacio que ocupa, situación, ventilación, etc. Suelen ser muy críticas y analizan las precarias instalaciones y comparan con las óptimas condiciones. Diversos edificios se utilizaron como establecimientos escolares, tales como salas del ayuntamiento, viviendas, casas viejas $\mathrm{y}$ antiguos conventos, viejos $\mathrm{y}$ antihigiénicos. El 90\% de las escuelas no reúnen las mínimas condiciones higiénicas y pedagógicas. Ni siquiera la escuela aneja cumplía los requisitos pedagógicos. De las instalaciones refieren que no corresponde a lo indicado por la pedagogía moderna, aulas pequeñas y poco ventiladas, patio del recreo pequeño e insuficiente (RODRÍGUEZ, 1937). Pocos edificios eran construcciones escolares propiamente dichas, si exceptuamos los grupos escolares de la capital. En Santa Cruz los edificios de las escuelas graduadas de San Fernando (DAVI, 1946; DELGADO, 1947), José Antonio (DÍAZ, 1947), Onésimo Redondo (COELLO, 1946; HERRÁIZ, 1943), Isabel la Católica (PALENZUELA, 1947) y 
García Escamez (DÉNIZ, 1948) habían sido construidos como tales, por lo que reunían las condiciones pedagógicas e higiénicas óptimas. El edificio de la escuela graduada de San Fernando es “modelo en su género" (DELGADO, 1947).

En ocasiones las dependencias eran dignas como espacio para albergar las escuelas. La escuela nacional graduada de niñas de Güimar ocupaba unas instalaciones que no eran propias de un edificio educativo, en cambio disponía de amplia sala, patio y servicio higiénico adecuado (CUBAS, 1947). Mientras había otras escuelas graduadas inadecuadas y con muchas deficiencias (HERNÁNDEZ, 1937; GROTE, 1938; RAMOS, 1943; BARBA, 1944; BARRIOS, 1947). Sorprende el hecho de que la escuela graduada aneja a la escuela de magisterio (escuela nacional de niñas $\mathrm{n}^{0} 1$ de La Laguna) sea señalada por no reunir las condiciones pedagógicas (DORTA, 1937; RODRÍGUEZ, 1937; GROTE, 1938). El edificio es "muy antiguo, antihigiénico y antipedagógico, lo que da lugar a que la enseñanza se realice en las peores condiciones" (RAMOS, 1943, p. 1). También detectaron las deficiencias en las escuelas unitarias de Tacoronte (BENCOMO, 1937), Puerto de la Cruz (HERNÁNDEZ, 1937), Garachico (CONTRERAS, 1946), Realejo Bajo (GARCÍA, 1937), Icod (BRAVO, 1944), Los Silos (DÁVILA, 1947; YANES, 1949). Situación idéntica se repetía en las escuelas unitarias de la isla de La Palma, en Santa Cruz (BRAVO, 1944), en Fuencaliente (RÍOS, 1943) y Puntallana (HERNÁNDEZ, 1947).

En general, se trataba de unas instalaciones viejas y deterioradas que no reunían las condiciones óptimas ni cumplían las recomendaciones pedagógicas para albergar a la infancia tantas horas diarias. Se repite el argumento de construcciones que no se edificaron como escuelas y presentan muchas deficiencias. Carecían de patio, agua corriente y "Wáter" (HERNÁNDEZ, 1947; GARCÍA, 1937; YANES, 1949). El patio era necesario como lugar de recreo, zona para juegos infantiles y para realizar los ejercicios de educación física: "donde las niñas cultivan plantitas y pueden distraerse en las horas de recreo" (BRAVO, 1944, p. 2). Por lo que el edificio no era una escuela pedagógica porque carecía de muchas cosas que debía poseer "pero ya sabemos que en España son pocas las 
escuelas que se encuentran en el estado que debiera, pues solamente las de moderna construcción son las perfectas, y estas no son por ahora muy abundantes... esperemos que el nuevo Estado dicte medidas encaminadas a reparar esta falta“" (BRAVO, 1944, p. 3).

La totalidad de las memorias describe la decoración de las clases. En todas las escuelas, unitarias y graduadas, urbanas y rurales estaban presentes, desde septiembre de 1936, los cuadros de Franco, José Antonio, la bandera y las imágenes religiosas. En las paredes también se colocaban los trabajos y murales realizados por las alumnas.

Igualmente el mobiliario lo componían la mesa y silla para la maestra, pupitres bipersonales para las alumnas, alguna estantería para libros, armario para material y un armario para guardar la documentación de la escuela (CAÑADAS, 1947; CASAS, 1944; DÁVILA, 1947; GARCÍA, 1937). Unos muebles se encontraban deteriorados y envejecidos, de manera que opinaban que debían ser sustituidos o que eran insuficientes para las necesidades de la escuela (SUÁREZ, 1947).

\section{MATERIAL}

El material escolar fungible incluía los útiles necesarios para realizar las tareas instrumentales, tales como cuadernos, lápices, gomas, lápices de colores, plumas, tinta, tinteros, tiza blanca y tizas de colores. También disponían de pizarras, figuras geométricas, globo terráqueo, mapas murales, compás, reglas, etc. de forma similar en todas partes. En la escuela graduada de Icod había cinco mapas del mundo, uno de España y dos mapas de Islas Canarias (BORGES, 1947). En Fuencaliente (La Palma) había una máquina de coser y bordar de la marca "Singer", 1 vitrina del sistema métrico decimal geométricos, 13 mapas geográficos, 7 pizarras murales (RÍOS, 1943). También en Güimar había una máquina de coser para el aprendizaje de las habilidades para la confección de 
prendas de vestir (CUBAS, 1947).

Todas las escuelas poseían una pequeña biblioteca y contaban con colecciones de libros, producto de la dotación realizada en etapas anteriores. Como libros de estudio indicaban las enciclopedias de Antonio Fernández en todos sus grados (HERNÁNDEZ, 1947) y enciclopedias de Dalmau y Salvat. Libros de consulta: colección Sopena (24 vol.), colección Labor, colección Xandry Pich, colección Seix Barral (Isabel la Católica, Cristóbal Colón, Hernán Cortés, Pizarro, Cervantes, Lope de Vega, Santa Teresa de Jesús, Santa y heroínas, Glorias Imperiales, Raza española), libros de Martí Alpera, Charentón, J. de Muro, Manuel Marinel-Lo (DORTA, 1937; GARCÍA, 1937), Misal (DÁVILA, 1947). Libros de lectura: Nuevas lecturas Patrióticas de Antonio Fernández, El Quijote, Lecciones de cosas, Glorias Imperiales de Luis Ortíz, Nueva emoción de España por M. Liurot, Así quiero ser de Hijos de Santiago Rodríguez, Catecismo Explicado y Evangelio Explicado de Llorente (DÁVILA, 1947; DORTA, 1937; GARCÍA, 1937; SOLER 1947), Viajes por España y Horizonte Imperial por Federico Torres, El cielo de Azcarza (HERNÁNDEZ 1937; BORGES, 1947; HERNÁNDEZ, 1947; SUÁREZ, 1947), Mari-sol, Así son nuestros niños, Las memorias de Pepito, Lectura mental activa (DÁVILA, 1947).

También en muchas escuelas existía un pequeño museo escolar que habían construido con objetos obtenidos en los paseos y excursiones escolares. Por ejemplo, en la escuela de niñas de Güimar había un museo con colecciones de minerales, materiales de ciencias naturales, esqueletos, aparatos de Física y Química (CUBAS, 1947). En la escuela graduada de Santa Cruz de La Palma había una colección variada de insectos, minerales, cereales, la mayor parte llevados por las niñas (RAMOS, 1943). Del mismo modo en Santa Cruz de Tenerife había un pequeño museo escolar, organizado por la maestra con ayuda de las niñas que recogían objetos en sus excursiones escolares (DÍAZ, 1947) o en Tacoronte que constituía un aporte importante de material didáctico (BENCOMO, 1937). 


\section{ORGANIZACIÓN ESCOLAR}

La religión y la patria eran los pilares básicos que sustentaban el nuevo modelo educativo, amparado en la tradición para servir a Dios y a la Patria (MARTÍN, 2010). Se restituyó la enseñanza confesional de perfil católico y se estableció la enseñanza obligatoria de la religión y la historia sagrada en todos los niveles, pero especialmente se actuó sobre la enseñanza primaria, dado que era fundamental conseguir la transformación social desde abajo.

La organización escolar era muy semejante. La jornada matutina dedicada preferentemente a las materias instrumentales y la vespertina a actividades que requerían menos esfuerzo mental. De manera que las mañanas se ocupaban con gramática (ejercicios de escritura, dictado, lectura), aritmética, geometría, historia y geografía con diversos ejercicios. Las tardes dedicadas a las labores, trabajos manuales, dibujo, educación física, religión, catecismo y formación patriótica. A las niñas se les enseñaba a coser, bordar y tejer "preparando a las niñas para su futura actuación en la vida como futuras madres y amas de casa" (PALENZUELA, 1947, p.11). Hubo casos en los que las niñas no tenían recursos para comprar una tela y los hilos y la maestra se lo proporcionaba (CONTRERAS, 1946). Aprendían a confeccionar ropa blanca, después a zurcir, remendar, coser y luego a bordar (CARRILLO, 1947). No ignoraban el rol asignado a las niñas, futuras mujeres, de ahí la importancia de las materias femeninas encaminadas a la formación para cumplir con su finalidad (COELLO, 1946): "La educación social tiende a formar a las niñas para el hogar cristiano... La Economía doméstica y las Labores tienden a formar en la niña una mujer conocedora de la forma de dirigir, llevar y constituir el hogar" (ÁLVAREZ, 1943, p.4).

En cada sesión de clase (mañana y tarde), a la entrada y salida, rezaban las oraciones (CARRILLO, 1947; CATALÁN, 1943). A la entrada oración de entrada y cánticos patrióticos, la oración de salida y cánticos patrióticos. Los sábados de forma obligatoria se explicaba se evangelio y en muchas escuelas 
rezaban el rosario. Las vísperas de festividades religiosas se explicaba el motivo y asunto de dicho santoral. Se repiten las rutinas diarias de entrada y salida, con rezos y los cánticos patrióticos, en las clases las lecturas patrióticas y exaltaciones al "movimiento nacional" (BARBA, 1944). Dedicaban 6 horas semanales a estudiar la patria, además de cantos (GARCÍA, 1937). Proporcionaban siempre conocimientos de moral religiosa y patriótica y "perseguía el objetivo de inculcar a las niñas el amor a Dios, a la Patria y a los semejantes" (GARCÍA, 1937, p. 7; BARRIOS, 1947, p.4).

La distribución horaria coincidía en todas las escuelas con el horario estándar de jornada dividida en dos sesiones. De lunes a viernes, por la mañana con el inicio de las clases a las 9 horas hasta las 12 horas, por la tarde entre las 2 y 4 horas, y el sábado de 9 a 12 horas. En algunas escuelas había clases los sábados por la tarde. Citar por ejemplo la escuela unitaria número 1 de La Laguna donde los sábados había horario de tarde completo (ÁLVAREZ, 1943; BUTRAGÜEÑO, 1946). En otras escuelas el sábado por la tarde ser reservaba para los paseos y excursiones como en la escuela de Puntallana (HERNÁNDEZ, 1947), mientras que en otras lo dedicaban al estudio de la doctrina cristiana, incluso iban a la iglesia y el cura hacía seguimiento a las niñas de su aprendizaje. Regularmente los sábados por la mañana se hacía lectura y explicación del evangelio, geografía, historia patria y gimnasia. Además del aprendizaje de los preceptos doctrinales, se transmitía la obligación de asistir a misa los domingos y fiestas de guardar.

Las matrículas de las escuelas nacionales de niñas eran elevadas. No obstante, no asistían todas las niñas inscritas, el absentismo escolar era notorio tanto en las zonas urbanas como rurales. Las causas de la baja e irregular asistencia escolar se situaban en la pobreza y el trabajo infantil (BENCOMO, 1937; BORGES, 1948; CONTRERAS, 1946; DORTA, 1937; GARCÍA, 1937; HERNÁNDEZ, 1947; RAMOS, 1943). En las áreas rurales se apreciaba mayor irregularidad en los periodos de zafras agrícolas (BENCOMO, 1937; GARCÍA, 1937). "Hay unos meses que se nota descenso en la asistencia, debido a la recolección de los frutos del campo; "defecto de todo pueblo agrícola" 
(BENCOMO, 1937, p. 6). "La causa de faltar las niñas a clase creo que son debidas a las faltas de recursos de los padres, que se ven obligados a servirse de sus hijos en faenas domésticas y algunas veces agrícolas" (RAMOS, 1943,p. 3). Manifestaban que las niñas ayudaban en las faenas de la casa o en otros trabajos, también sirviendo en otras casas particulares para ganarse el sustento, la comida y vestidos (CONTRERAS, 1946). Además señalaron que debido a la pobreza muchas niñas "carecían de ropa para asistir a la escuela, pudiéndose subsanar esta insuficiencia si se creara un Ropero escolar" (HERNÁNDEZ, 1947, p. 3).

\section{LOS MÉTODOS DE ENSEÑANZA EMPLEADOS}

La Circular del Ministerio de Educación Nacional de 8 de marzo de 1938 (BOE, 1938) fijaba el programa a desarrollar en las escuelas hasta la aprobación de la Ley de Enseñanza Primaria de 1945 (BOE, 1945). Los programas de todas las materias estaban impregnados por el nacionalcatolicismo de forma transversal. La cultura pedagógica nacional-católica se proyectaba en los temas tratados, desde gramática, aritmética, historia, geografía, ciencias naturales, educación física, a las conmemoraciones, rezos, liturgia y evangelio. Los contenidos se estructuraban en torno a cuatro ejes: cívico, religioso, patriótico y físico. Los programas y manuales legitimaban la educación con el potencial ideológico, la política y la moral cristiana. Los manuales escolares que acreditaban los saberes eran los libros de texto oficiales, que servían de fundamento ideológico a la praxis educativa, dictaban el modelo a seguir en las escuelas para asegurar la pervivencia de las directrices marcadas por las autoridades educativas, para no trastocar el ordenamiento político y cumplir con su función social. Si bien marcaban restricciones en el saber debido al control, la manipulación y a la censura de los contenidos. El contenido se regía por el nacionalcatolicismo y las orientaciones tradicionales, pero las formas de enseñar eran más flexibles y adaptadas a las niñas. La pervivencia de los modelos pedagógicos en la práctica escolar era una constante, más que rupturas con el 
periodo anterior, a tenor de la información extraída de las memorias. Si bien la religión y la enseñanza patriótica, con sus manifestaciones externas, respondían fielmente a los principios del movimiento nacional desde la óptica femenina. El magisterio cumplía con las indicaciones educativas y respetaba las normas, pero la metodología parece que no estaba bajo ese control. Las maestras se declaraban defensoras del nacionalcatolicismo y al mismo tiempo de la pedagogía activa. Las alumnas de prácticas recogen en sus memorias los acontecimientos y metodologías más destacadas del hacer en el aula, de lo que algunos historiadores de la educación han denominado "cultura empírica de la escuela" (ESCOLANO, 2008).

Con la vuelta a los valores conservadores del viejo orden, y en función de la ideología del régimen dictatorial, se marcaron los patrones educativos. La pedagogía autoritaria de signo católico imbuía los nuevos esquemas del pensamiento de los pedagogos del régimen. Sin embargo, a pesar de las consignas, la pedagogía activa e intuitiva no se apagó. La cultura empírica de la escuela de las primeras décadas lo evidencia y así lo reflejan todas las memorias. Los usos metodológicos no habían cambiado, aunque se incluyeran las manifestaciones ideológicas y religiosas en la práctica escolar diaria. El énfasis en la educación emocional patriótica y católica caló en la educación que recibían las niñas. Las maestras interiorizaban los modelos y pautas impuestas para difundirlas en las escuelas pero los métodos no variaron durante ni después de la guerra. Uno de los ejercicios habituales eran los centros de interés decrolianos, en ocasiones denominados "lecciones de cosas". Los procedimientos activos e intuitivos como base de la práctica de enseñanza, resultante de los movimientos de renovación pedagógica extranjeros, no se interrumpieron durante la guerra y postguerra.

Muchos ejemplos demuestran el empleo de una pedagogía activa que entroncaba con la pedagogía y metodologías de la escuela nueva, hecho que representaba una continuidad de la renovación pedagógica ensayada durante la etapa anterior. A pesar que el régimen desacreditó la introducción de las ideas de 
pedagogos extranjeros (Rousseau, Decroly, Montessori, Fröebel) seguían vigentes en las prácticas del aula. Es cierto que una parte del magisterio que ejerció durante la guerra y en la posguerra había recibido formación académica con el plan de 1914 y el plan profesional de 1931, que interiorizaron las recomendaciones de la moderna pedagogía, y no rechazaron su uso ante las consignas recibida de las autoridades franquistas. El modelo de la pedagogía católica y de los pedagogos Andrés Manjón, Luis Vives y Calasanz eran los ejemplos a imitar. Por ello algunas estudiantes criticaban a los pedagogos extranjeros, manifestando que "ha sido una realidad dolorosa, que en tiempos nefastos se viera todo a través de pedagogo extranjeros, habiéndolos y teniéndolos, tan buenos o mejores" (RÍOS, 1943, p. 12). La educación moral y religiosa se fundamentaba en "la teoría del Padre Manjón” (DÁVILA, 1947). La aversión por la renovación pedagógica no se reflejó en la primera década; caló más tarde y de forma progresiva entre los maestros y maestras formadas con los planes de estudio posteriores, es decir, con los programas del plan 1942 y 1945. No obstante, diversas memorias están acompañadas de las hojas de preparación de clases, es decir, que planificaban la lección de las materias a impartir y en ella se reflejaba la metodología activa (CARRILLO, 1947; COELLO, 1946; DELGADO, 1945).

De este modo, buena parte de la pedagogía activa continuó presente en la escolaridad. Las lecciones de cosas o centros de interés se practicaron durante el periodo de la guerra y posguerra (BORGES, 1948; DORTA, 1937). Los métodos de Decroly fueron empleados en todas las materias en la escuela de prácticas aneja a la escuela de magisterio. También empleaban como recurso los cuadernos de rotación y el diario de clases (DELGADO, 1945). Pero las innovaciones se observan en las clases de historia y geografía, con las narraciones, las lecturas de cuentos. Utilizaron el teatro y las representaciones de comedias infantiles para desarrollar la capacidad de expresión (DÍAZ, 1945). Tampoco faltaron las conmemoraciones, los centros de interés o temas del día, las visitas y excursiones muestran algunos rasgos de la pedagogía renovadora que pervivió con el franquismo. En la práctica pedagógica seguían el desarrollo progresivo de las 
lecciones, según el grado, y empleaban el método intuitivo en los primeros grados. Para matemáticas empleaban el método analítico, intuitivo y activo (GARCÍA, 1937; BARRIOS, 1947). En ocasiones empleaban el método individual cuando asistían pocas niñas (CONTRERAS, 1946). Combinaban diferentes métodos adaptándose a la realidad de las alumnas. Por ejemplo, el método analítico en complemento con el sintético (BUTRAGÜEÑO, 1949) o el método activo con procedimiento intuitivo (ÁLVAREZ, 1943; BARRIOS, 1947; CARRILLO, 1947; DELGADO, 1947; DORTA, 1937). Los procedimientos verbalista y socrático para las enseñanzas de doctrina cristiana, historia, educación social, educación patriótica y del movimiento. Recurrían al método expositivo, intuitivo y activo "procurando no hacer del método una rigidez extrema, sino que interviene también la parte personal de la maestra" (ÁLVAREZ, 1943, p. 5).

El método intuitivo práctico lo aplicaban en la enseñanza de la geografía, así partían del estudio del pueblo, escuela, casa, edificio, calle del barrio, la ciudad (DORTA, 1937). Geografía, historia, educación patriótica. Tres materias que relacionaban porque consideraban fundamental, "una nación sin historia con su formación política no tiene existencia real". Como material de apoyo para explicar los temas de geografía utilizaban mapas, fotografías, globo terrestre para conocer los países, las grandes ciudades y las capitales. La historia la enseñaban por medio de sencillas narraciones en las que se procuraba ante todo inspirarles el amor a la patria "como algo noble y heredado de nuestros antepasados" (DORTA, 1937, p. 11). La metodología para la enseñanza de la religión y catecismo se hacía con narraciones y explicaciones, memorizaciones de la doctrina cristiana y celebraciones religiosas. En el mes de mayo, el mes de María, se realizaban los rituales a la virgen María, pequeño altar con flores hecho por la maestra y las niñas, se entonan cánticos y rezos. Al finalizar la clase cantaban, rezaban y pedía por España y su Caudillo (BARRIOS, 1947; COELLO, 1946; PALENZUELA, 1947).

Las excursiones y paseos se impulsaban desde las esferas oficiales, dados 
los beneficios para la salud infantil y a la vez para el aprendizaje. Los paseos y excursiones de carácter didáctico eran actividades frecuentes (GARCÍA, 1937; CAÑADAS, 1947; CATALÁN, 1943). Hacían paseos al mar y al campo para relacionar la naturaleza con los temas estudiados de geografía o ciencias naturales desarrollando lecciones ocasionales: "Los paseos escolares y excursiones por el campo, son de un gran valor pedagógico, desde el punto de vista de la educación completa" (DORTA, 1937, p.12). No sólo realizaban paseos por el entorno de la escuela también por distintas zonas de la isla, entre los más destacados la visita al monte de agua García y al jardín botánico (BARRIOS, 1947; HERNÁNDEZ, 1937). Una alumna de prácticas expresaba que "la escuela unitaria tiene que tener vitalización; para ello hay que sacarla del estrecho ambiente del salón de clase y llevarla a la calle, al seno de la familia, al campo, al taller, a la fábrica, a la oficina, a todos los lugares y a todos los medios en el que el niño vive o puede vivir" (BENCOMO, 1937, p. s/p. ).

\section{CONCLUSIONES}

Las memorias de prácticas reglamentarias y obligatorias redactadas por las alumnas de magisterio, se convierten en el testigo del acontecer cotidiano de las escuelas. Recogen las observaciones directas como protagonistas y desde su atalaya se implican en el proceso enseñanza-aprendizaje. En el caso que nos ocupa, como aprendizas de maestras, sus narraciones nos introducen en las rutinas escolares, en la metodología, programas, lecciones, actividades, las condiciones higiénicas del edificio pero también en las ideas y creencias de una escuela controlada por el nacionalcatolicismo. A través del espejo de las memorias de prácticas de las alumnas de magisterio de La Laguna nos sumergirnos en la escuela entre 1936 y 1949, nos acercan a la realidad escolar de Canarias pero también a la escolaridad de España en ese periodo. La exploración de la actividad escolar diaria y de la metodología que a la vez permite conocer los modos de enseñar. El relato nos lleva más allá de lo meramente académico para 
situarnos en el plano de la vida cotidiana de la infancia, de las economías familiares y de las privaciones de las niñas, en una etapa en la que el trabajo infantil impedía ir a la escuela o tener una escolaridad fragmentada. No ignoramos que el trabajo infantil aún se mantenía en la década de los años setenta.

Dado que en el Archipiélago Canario no hubo tregua en 1936, se finaliza el curso bajo gobierno republicano y se comienza bajo el yugo de una dictadura militar (GONZÁLEZ, 2000). A través de las memorias de prácticas de las alumnas de magisterio podemos comprobar que las directrices doctrinarias se impusieron de forma inmediata. En cambio hubo más continuidades que rupturas con el modelo anterior y siguieron aplicando el modelo innovador de la escuela nueva. Las maestras se habían formado antes de la guerra y de ahí la pervivencia e la metodología. No se aprecia un pensamiento divergente en el contenido de las memorias de prácticas, ni siquiera en aquellas redactadas durante los años de la guerra. Las alumnas narran con naturalidad los acontecimientos más significados de su experiencia escolar y valoran positivamente el quehacer de las maestras en su actividad cotidiana. Ellas se muestran humildes con su vocación y sus buenos propósitos, incluso se encomiendan a Dios para que les guíe en el desarrollo de la profesión.

Las memorias no presentan una uniformidad pero existe una semejanza en el conjunto de elementos que aportan. En se esencia destacar el reflejo de la metodología, revelando la pervivencias de métodos e innovaciones que no hubo ruptura con la pedagogía activa y continuaron empleando muchos de los recursos. No se anularon las formas de enseñar aunque se incorporó el programa educativo del régimen autoritario. El ritual de entrada y salida de clase, rezos y cánticos patrióticos. La subida de bandera matutina con el canto del "cara al sol" con el brazo en alto era una fórmula idéntica en todas las escuelas públicas de Canarias, igual a las escuelas de otras zonas de España. El canto del himno y canciones patrióticas, la celebración de homenajes, festividades patrias y religiosas fue común y generalizado. En todas las escuelas quedaba patente la 
enseñanza y el aprendizaje de las niñas de las materias consideradas femeninas (labores, higiene y habilidades domésticas) importantes para su misión como mujeres. Un aprendizaje prioritario junto a las materias instrumentales y los principios ideológicos del nacionalcatolicismo. Tanto las maestras en prácticas como las maestras titulares tenían muy asumidos los valores morales y prácticas religiosas así como los postulados y principios del nacionalcatolicismo. Los dogmas que reproducían el discurso ideológico eran transmitidos a las niñas. Además de los roles de género y actividades sexuadas en un contexto donde prevalecía la vida hogareña y donde las maestras eran modelos de mujer a imitar (GONZÁLEZ, 2001).

Por otra parte, en un colectivo como el del magisterio represaliado y escarmentado, no era de esperar otras formas que la fiel reproducción ideológica de los principios del nacionalcatolicismo. Por lo general, a través de las memorias se observa una actitud muy receptiva y muy positiva, reconociendo la importancia pero en ninguna se cuestiona o se duda. También es cierto que las memorias se evaluaban y debían cumplir con unos mínimos requisitos y ni siquiera se planteaban subvertir el orden. El aparato ideológico insular funcionaba a la perfección y con buenos resultados, tras la represión desplegada contra la población republicana o no afecta al nuevo orden. Castigada de múltiples formas, como sucedió en otras zonas. Quizá hasta con mayor dureza se escarmentó a la población insular desde el mismo 18 de julio de 1936, según acreditan diversos especialistas (RIVAS, 2015). El autoritarismo pedagógico no se proyectó en las memorias. No encontramos referencias a faltas de disciplina y castigos, realmente al tratarse de escuelas de niñas el ambiente era más tranquilo por el control que se ejercía sobre ellas. En cambio se repite con insistencia el absentismo escolar y la baja asistencia.

El escaso protagonismo que se confería a las maestras en formación, cuya tarea se limitaba a una labor de observación de la realidad escolar y del trabajo de la maestra, con pequeñas prácticas. Sin embargo a través de las memorias han sido capaces de inmortalizar un periodo de la historia educativa española. Como 
fuentes las memorias suministran una nutrida información que enriquece el conocimiento y las líneas de investigación. El análisis abre posibilidades a la ampliación del conocimiento y la investigación a través del estudio de estos documentos inéditos, que pueden extrapolarse a otros periodos y contextos.

Para finalizar añadir que las memorias de prácticas constituyen un aporte importante para la historia de la educación, en concreto el para el estudio histórico de la práctica escolar durante la guerra y la postguerra al tiempo que nos acerca al estudio empírico de la escuela.

\section{REFERENCIAS}

ÁlVAREZ, Amparo. Memoria de Prácticas. Escuela unitaria n. 1. La Laguna. Tenerife, 1943, 7 pp.

BARBA, Eusebia. Memoria de Prácticas. Escuela unitaria n. 1. La Laguna. Tenerife, 1944, s/p.

BARCELÓ, Gabriel; COMAS, Francisca; POZO, María Mar. La práctica escolar durante los primeros años del franquismo. História da Educação, Vol. 22, n. 54, p. 334-357, 2018. Disponible em: https://www.redalyc.org/jatsRepo/3216/321660489020/html/index.html.

BARCELÓ, Gabriel; COMAS, Francisca; SUREDA, Bernat. Abriendo la caja negra: la escuela pública española de postguerra. Revista de Educación, n. 371, p. 61-82, 2016. Disponible em:

https://dialnet.unirioja.es/servlet/articulo?codigo $=5327943$

BARRIOS, Candelaria. Memoria de Prácticas. Escuela unitaria n. 1. La Laguna. Tenerife, 1947, s/p.

BENCOMO, María Josefa. Memoria de Prácticas. Escuela unitaria de Los Naranjeros. Tacoronte, 1937, s/p.

BOLETÍNES Oficiales de la Provincia de Santa Cruz de Tenerife, de 9 de septiembre, de 4 y 9 de diciembre de 1936.

BORGES, María Carmen. Memoria de Prácticas. Escuela unitaria n. 2. Icod de los Vinos. Tenerife, 1948, 8 pp. 
BRASTER, Sjaak; GROSVENOR, Ian; DEL POZO ANDRÉS, María del Mar (ed.) (2011). The Black Box of Schooling: A Cultural History of the

Classroom. Brussels: Peter Lang, 2011.

BRAVO, Eugenia. Escuela nacional n. 6. Santa Cruz de La Palma, 1944, 7 pp.

BUTRAgueÑo, María Carmen. Memoria de Prácticas. Escuela unitaria ${ }^{\circ}$ 1. La Laguna. Tenerife, 1946, s/p.

CABRERA, Argelia. Memoria de Prácticas. Escuela graduada de San Fernando. Santa Cruz de Tenerife, 1941, 18 pp.

CABRERA, Elena. Memoria de Prácticas. Escuela unitaria n. 2. La Laguna. Tenerife, 1945, s/p.

CABRERA, Escolástica. Memoria de Prácticas. Escuela de la Cuesta. La Laguna. Tenerife, 1947, 6 pp.

CABRERA, María Toribia. Memoria de Prácticas. Escuela de Mazo. La Palma, 1947, s/p.

CABRERA, Olga. Memoria de Prácticas. Escuela graduada Onésimo Redondo. Santa Cruz de Tenerife, 1945, s/p.

CALDERÓN, Ciriaca. Memoria de Prácticas. Escuela nacional n. 6. Santa Cruz de La Palma, 1948, s/p.

CAÑADAS, Raquel. Memoria de Prácticas. Escuela de los Lavaderos. Santa Cruz de Tenerife, 1947, s/p.

CARRERA, María. Memoria de Prácticas. Escuela mixta de Barranco Las Lajas. Tacoronte. Tenerife, 1948, s/p.

CARRILlO, María Asunción. Memoria de Prácticas. Escuela nacional de n. 4. Santa Cruz de La Palma, 1947, s/p.

CASAS, Ana. Memoria de Prácticas. Escuela nacional n. 2. Adeje. Tenerife, $1947, \mathrm{~s} / \mathrm{p}$.

CASAS, Eulalia. Memoria de Prácticas. Escuela nacional n. 5. Santa Cruz de La Palma, 1947, s/p.

CATALÁN, Serena. Memoria de Prácticas. Escuela mixta de Geneto. La Laguna. Tenerife, 1943, s/p.

COELLO, María. Memoria de Prácticas. Escuela graduada Onésimo Redondo. Santa Cruz de Tenerife, 1946, s/p. 
CONTRERAS, Esther. Memoria de Prácticas. Escuela n. 3. Garachico. Tenerife, 1946, $35 \mathrm{pp}$.

CUBAS, Erudina. Memoria de Prácticas. Escuela graduada. Güimar. Tenerife, 1947, s/p.

DARIAS, María Carmen. Memoria de Prácticas. Escuela graduada. Tacoronte. Tenerife, 1944, s/p.

DAROCA, Mercedes. Memoria de Prácticas. Escuela graduada Onésimo Redondo. Santa Cruz de Tenerife, 1940, s/p.

DAVI, Irene. Memoria de Prácticas. Escuela graduada José Antonio. Santa Cruz de Tenerife, 1946, s/p.

DÁVILA, Sara. Memoria de Prácticas. Escuela nacional n. 3. Los Silos. Tenerife, 1947, s/p.

DEL POZO, María del Mar; RABAZAS, Teresa. Políticas educativas y prácticas escolares: la aplicación de la Ley de Enseñanza Primaria de 1945 en las aulas. Bordón, 65, n.4, p. 119-133, 2013.

DELGADO, Elena. Memoria de Prácticas. Escuela mixta de Taco. La Laguna. Tenerife, 1947, s/p.

DELGADO, Evarista. Memoria de Prácticas. Escuela unitaria n. 2. La Laguna. Tenerife, 1945, s/p.

DELGADO, María. Memoria de Prácticas. Escuela mixta de San Bartolomé. La Laguna. Tenerife, 1949, s/p.

DÉNIZ, María Jesús. Memoria de Prácticas. Escuela Graduada García Escámez. Santa Cruz de Tenerife, 1948, 7 pp.

DÍAZ, Carmen. Memoria de Prácticas. Escuela unitaria de Los Naranjeros. Tacoronte. Tenerife, 1945, s/p.

DÍAZ, Reneida. Memoria de Prácticas. Escuela graduada José Antonio. Santa Cruz de Tenerife, 1947, s/p.

DORTA, Natividad. Memoria de Prácticas. Escuela graduada aneja. La Laguna. Tenerife, 1937, $17 \mathrm{pp}$.

ESCOLANO, Agustín (Coord.). La cultura material de la escuela: en el centenario de la Junta para la Ampliación de Estudios, 1907-2007. Berlanga de Duero: Centro Internacional de la Cultura Escolar, 2007. 
ESCOLANO, Agustín. La cultura empírica de la escuela aproximación etnohistórica y hermenéutica. En: MAINER, Juan (Coord.). Pensar críticamente la educación escolar: perspectivas y controversias historiográficas. Zaragoza: Universidad de Zaragoza, 2008, p. 145-172.

ESCOLANO, Agustín. La cultura material de la escuela y la educación patrimonial. Educatio Siglo XXI, 28, 2, p. 43-64, 2010.Disponible em: https://revistas.um.es/educatio/article/view/111961.

FERNÁNDEZ SORIA, Juan Manuel; AGULLÓ, Carmen. Los temas educativos en las Memorias del Magisterio Valenciano (1908-1909). Valencia: Universitat de València, 2002.

GARCÍA, Matilde. Memoria de Prácticas. Escuela nacional de Tigaiga. Los Realejos. Tenerife, 1937, s/p.

GONZÁLEZ PÉREZ, Teresa. Maestras españolas en el franquismo: protagonistas olvidadas. REXE: Revista de estudios y experiencias en educación, 13 -25, p. 107-124, 2014.

GONZÁLEZ PÉREZ, Teresa. La educación insular durante el franquismo, Tebeto, n. 18, p. 411-436, 2005.

GONZÁLEZ PÉREZ, Teresa. La formación de las mujeres en la posguerra española: Canarias como ejemplo. Bordón, 53- 3, p. 369-386, 2001.

GONZÁLEZ PÉREZ, Teresa. Las Escuelas Normales en la Laguna: 1936-1946. Una década en la formación del Magisterio. Anuario de Estudios

Atlánticos, 46, p. 167-234, 2000. Disponible em: http://anuariosatlanticos.casadecolon.com/index.php/aea/article/view/770/77 o.

GROTE, María Carmen. Memoria de Prácticas. Escuela graduada aneja. La Laguna. Tenerife, 1938, $13 \mathrm{pp}$.

HERNÁNDEZ, Daniela. Memoria de Prácticas. Escuela unitaria de Puntallana. La Palma, 1947, 7 pp.

HERNÁNDEZ, María. Memoria de Prácticas. Escuela graduada aneja. La Laguna. Tenerife, 1937, s/p.

HERnÁNDEZ, María Aflijidos. Memoria de Prácticas. Escuela n. 2 del Puerto de la Cruz. Tenerife, 1937, s/p.

HERRÁIZ, María Carmen. Memoria de Prácticas. Escuela graduada 
Onésimo Redondo. Santa Cruz de Tenerife, 1943, s/p.

INSTANCIAS de Solicitud de Prácticas. Caja 140.

INSTANCIAS de Solicitud de Prácticas. Caja 140.

LIBROS de registro de Matrícula de Alumnas de Enseñanza no Oficial.

LIBROS de registro de Matrícula de Alumnas de Enseñanza no Oficial.

LIBROS de registro de Matrícula de Alumnas de Enseñanza Oficial.

LIBROS de registro de Matrícula de Alumnas de Enseñanza Oficial.

LÓPEZ, Juan Ramón. La escuela azul de Falange Española de las

J.O.N.S.: Un proyecto fascista desmantelado por implosión.

Santander: Dykinson/Ediciones Universidad Cantabria, 2017.

MARTÍN, Bienvenido y RAMOS, Isabel. La formación práctica del magisterio republicano a través de los cuadernos de memorias. En: Coloquio de Historia de la Educación,19, 19-21 de septiembre. Anais... Madrid: Universidad de Alcalá, 2017, p. 421-423.

MARTÍN, Bienvenido y RAMOS, Isabel. La memoria de los maestros: la cultura empírica transmitida por los docentes. Studia Zamorensia, n. 16, p. 27-38, $2017 \mathrm{~b}$.

MARTÍN, Bienvenido. La transmisión de valores patrióticos y cívico-sociales en el franquismo. Análisis de los cuadernos de rotación. Revista de Ciencias de la Educación, n. 221, p. 7-32, 2010.

MARTÍN, Bienvenido. La cultura escolar y el oficio de maestro. Educación XX1, v. 18, n. 1, p. 147-166, 2015.

MARTÍN, Bienvenido. Teorías educativas que subyacen en las prácticas docentes. Teoría de la Educación, Vol. 23, n. 1, p. 45-70, 2011.

MARTÍN, Bienvenido. Testimonios de maestros. Modelos y prácticas. Salamanca: Universidad de Salamanca, 2017.

MORENTE, Francisco. La muerte de una ilusión: el magisterio español en la Guerra Civil y el primer franquismo. Historia y comunicación social, n. 6 , p. 187-201, 2001.

PALENZUELA, Felicia. Memoria de Prácticas. Escuela graduada Isabel la Católica. Santa Cruz de Tenerife, 1947, s/p. 
PÉREZ, Marta. Memoria de Prácticas. Memoria de Prácticas. Escuela graduada aneja. La Laguna. Tenerife, 1937, s/p.

RAMOS, Dolores. Memoria de Prácticas. Escuela nacional $\mathrm{n}^{\mathbf{0}} \mathbf{1}$ de La Laguna. Tenerife, 1943, 13pp.

RAMOS, Petra. Memoria de Prácticas. Escuela graduada aneja de La Laguna. Tenerife, $1937, \mathrm{~s} / \mathrm{p}$.

RÍOS, Victoria. Memoria de Prácticas. Escuela unitaria de Fuencaliente. La Palma, 1943, 14 pp.

RIVAS, Ramiro. La Guerra Civil en Tenerife. Tesis Doctoral Inédita.

Programa de Doctorado de Historia. Departamento de Geografía e Historia. Universidad de La Laguna, 2015, 2.802 pp

RODRÍGUEZ, Marta. Memoria de Prácticas. Escuela graduada aneja de La Laguna. Tenerife, 1937, s/p.

SOLER, María Carmen. Memoria de Prácticas. Escuela graduada de Garachico. Tenerife, 1947, s/p.

SUÁREZ, Soledad. Memoria de Prácticas. Escuela n. 1 de la Villa de Los Silos. Tenerife, 1947, s/p.

YANES, Dulce. Memoria de Prácticas. Escuela n. 3 de Los Silos. Tenerife, 1949, s/p.

TERESA GONZÁLEZ-PERÉZ es Profesora Catedrática de Historia de la Educación. Área de Teoría e Historia de la Educación. Universidad de La Laguna (Tenerife Islas Canarias- España). Imparte docencia en la Facultad de Educación, en los grados de Pedagogía y Magisterio, en Máster y Doctorado. Su línea de investigación se circunscribe a la historia de la educación y dentro de ella, con preferencia, a la historia regional, a la educación de las mujeres y a los estudios culturales. Cuenta con numerosas publicaciones en revistas nacionales e internacionales, así como diversos libros y capítulos de libros. Participa regularmente en encuentros científicos, cursos y seminarios nacionales e internacionales. Miembro de distintos comités y entidades científicas colabora con redes de investigadores internacionales.

E-mail: teregonz@ull.es

(1) http://orcid.org/0000-0001-9132-4905 
Recebido em: 31 de março de 2020

Aprovado em: 07 de julho de 2020

Editora responsável: Tatiane de Freitas Ermel

\begin{tabular}{|c|c|}
\hline & $\begin{array}{l}\text { Revista História da Educação - RHE } \\
\text { Associação Sul-Rio-Grandense de Pesquisadores em História da Educação - Asphe }\end{array}$ \\
\hline BY & Artigo de acesso aberto distribuído nos termos de licença Creative Commons. \\
\hline
\end{tabular}

